\title{
Preliminary results of the performance of grounding electrodes encased in bentonite- mixed concrete
}

\begin{abstract}
Earth resistance of buried steel cages, encased in bentonite mixed concrete has been investigated. A reference pit was constructed with steel cage encasing in ordinary concrete. The land mass of the site has somewhat uniform surface soil resistivity which is in the range of $100 \mathrm{qm}$. The performance of earth resistance in each electrode has been measured for five months. The results show that for the first month, the lowest earth resistance and the highest decrement in earth resistance are shown by the pit with concrete having $20 \%$ bentonite. However, for the following four months, pits with bentonite mixed concrete showed increased earth resistance compared to the reference pit. These results indicate that the longterm reduction in earth resistance in electrodes encased with bentonite, as observed in previous studies, is not the case with electrodes embedded in bentonite mixed concrete. The initial reduction of earth resistance observed at pits with bentonite mixed concrete may most probably be due to the presence of hydrated bentonite which is not mixed with other constituents of concrete. Other than the pits with $20 \%$ and $70 \%$ bentonite, the outcome of this research thus far reaffirms the capability of concrete blocks to maintain earth resistance with small fluctuation.
\end{abstract}

Keyword: Soil resistivity; Bentonite; Grounding; Lightning protection; Ufer ground 